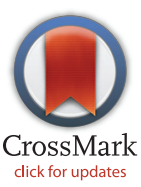

RESEARCH ARTICLE

\section{Are the Recent Secular Increases in Waist Circumference among Children and Adolescents Independent of Changes in BMI?}

\author{
David S. Freedman $^{1 \odot *}$, Brian K. Kit ${ }^{2 \odot}$, Earl S. Ford ${ }^{3 \odot}$ \\ 1 Division of Nutrition, Physical Activity, and Obesity, Centers for Disease Control and Prevention, Atlanta, \\ GA, United States of America, 2 Division of Health and Nutrition Examination Surveys, National Center for \\ Health Statistics, Centers for Disease Control and Prevention, Hyattsville, MD, United States of America, \\ 3 Division of Population Health, Centers for Disease Control and Prevention, Atlanta, GA, United States of \\ America \\ ه These authors contributed equally to this work. \\ *dxf1@cdc.gov
}

\section{Abstract}

\section{G openaccess}

Citation: Freedman DS, Kit BK, Ford ES (2015) Are the Recent Secular Increases in Waist Circumference among Children and Adolescents Independent of Changes in BMI? PLOS ONE 10(10): e0141056. doi:10.1371/journal.pone.0141056

Editor: Guoying Wang, Johns Hopkins Bloomberg School of Public Health, UNITED STATES

Received: May 8, 2015

Accepted: September 6, 2015

Published: October 27, 2015

Copyright: This is an open access article, free of all copyright, and may be freely reproduced, distributed, transmitted, modified, built upon, or otherwise used by anyone for any lawful purpose. The work is made available under the Creative Commons CCO public domain dedication.

Data Availability Statement: All data described in this paper are available for public use through the website http://www.cdc.gov/nchs/nhanes/nhanes questionnaires.htm. This page gives the data for each 2-year cycle since 1999-2000 (e.g., http://wwwn.cdc. gov/nchs/nhanes/search/nhanes99_00.aspx); the 1988-1994 data is available at http://www.cdc.gov/ nchs/nhanes/nh3data.htm. Investigators should consult http://www.cdc.gov/nchs/tutorials/Nhanes/ index_continuous.htm for information on analyses.

Funding: The authors have no support or funding to report.

\section{Background}

Several studies have shown that the waist circumference of children and adolescents has increased over the last 25 years. However, given the strong correlation between waist circumference and BMI, it is uncertain if the secular trends in waist circumference are independent of those in BMI.

\section{Methods}

We analyzed data from 6- to 19-year-olds who participated in the 1988-1994 through 2011-2012 cycles of the National Health and Nutrition Examination Survey to assess whether the trends in waist circumference were independent of changes in BMI, race-ethnicity and age.

\section{Results}

Mean, unadjusted levels of waist circumference increased by $3.7 \mathrm{~cm}$ (boys) and $6.0 \mathrm{~cm}$ (girls) from 1988-94 through 2011-12, while mean BMl levels increased by $1.1 \mathrm{~kg} / \mathrm{m}^{2}$ (boys) and $1.6 \mathrm{~kg} / \mathrm{m}^{2}$ (girls). Overall, the proportional changes in mean levels of both waist circumference and BMI were fairly similar among boys (5.3\%, waist vs. $5.6 \%$, BMI) and girls (8.7\%, waist vs. $7.7 \%$, BMI). As assessed by the area under the curve, adjustment for BMI reduced the secular increases in waist circumference by about $75 \%$ (boys) and $50 \%$ (girls) beyond that attributable to age and race-ethnicity. There was also a race-ethnicity interaction $(p<0.001)$. Adjustment for BMI reduced the secular trend in waist circumference among non-Hispanic $(\mathrm{NH})$ black children (boys and girls) to a greater extent (about $90 \%$ ) than among other children. 
Competing Interests: The authors have declared that no competing interests exist.

Abbreviations: ADHD, attention-deficithyperactivity disorder; BMI, body mass index; $\mathrm{CDC}$, Centers for Disease Control; NH, non-Hispanic; NHANES, National Health and Nutrition Examination Survey; WHtR, waist to height ratio

\section{Conclusions}

Our results indicate that among children in the U.S., about $75 \%$ (boys) and $50 \%$ (girls) of the secular increases in waist circumference since 1988-94 can be accounted for by changes in BMI. The reasons for the larger independent effects among girls and among $\mathrm{NH}$ blacks are uncertain.

\section{Introduction}

The prevalence of childhood obesity, defined as a BMI $\geq 95^{\text {th }}$ percentile of the CDC growth charts [1,2], among 6- to 19-year-olds in the U.S. increased from about 4.5\% in the 1960s [3] to about 20\% in 2011-12 [4]. Secular increases among 2- to 5-year-olds have been smaller, with the prevalence of obesity increasing from $5 \%$ in $1971-74$ [3] to $12.1 \%$ in $2009-10$, but then falling to $8.4 \%$ in 2011-12 [4]. The secular trends in obesity, among both children and adults, have slowed over the last 10 to 15 years $[4,5]$.

Although BMI may be as strongly correlated with some metabolic complications as is body fatness [6-9], several consequences of obesity may be more strongly associated with the amount of abdominal (or visceral) fat [10]. For example, several investigators have found that the waist circumference (either alone or in conjunction with other body measures) of adults may be a better predictor of adverse health outcomes than is BMI [11-15]. Among children, several studies have found that waist circumference and BMI have very similar abilities to identify children who have an adverse cardio-metabolic risk profile [16,17]. The very strong correlation ( $r \sim 0.9)$ between BMI and waist circumference, among both children and adults, however, complicates the assessment of the independent effects of body fat distribution [18].

As is the case for adults [19-22], the waist circumference of children in several countries has increased in recent decades $[19,20,23-25]$ and a recent review concluded that the secular increases in waist circumference have been larger than those for BMI [20]. These increases in abdominal obesity have been attributed to various factors, including changes in energy intake and physical activity, increased stress, and endocrine disruptors [26-28]. However, it is possible that much of the secular increase in waist circumference is no greater than what would be expected given the increases that have occurred in BMI. The objective of the current study is to assess the extent to which the recent trends in waist circumference among children are independent of changes in BMI.

\section{Methods}

We used data from the National Health and Nutrition Examination Survey (NHANES) from 1998-94 (NHANES III) and from the 72 -year cycles that have been conducted from 19992000 through 2011-2012 [29]. NHANES employs a multi-stage, stratified, cluster sampling design to select a representative sample of the US civilian, non-institutionalized population. The surveys were approved by the ethics review board, and parental permission was obtained for minors under the age of 18 years. 7- to 17-year-olds were also asked to provide documented assent, and consent was obtained for subjects who were $\geq 18$ years of age. Age was calculated as age in months at the time of examination.

Preliminary analyses indicated that the secular trends in the body size measures were much greater among 6- to 19-year-olds than among 2- to 5-year-olds, these younger children are not included in the current analyses. We focus on 6- to 19-year-olds who had measurements of 
height, weight and waist circumference $(n=26,433)$. Race and ethnicity were self-reported, and for these analyses, participants are classified as non-Hispanic (NH) white, NH black, Mexican-American, or other (which includes Hispanics from other countries and persons who reported more than 1 race). The response rates varied by the year of survey cycle, but the unweighted response rates for the examined 6- to 19 -year-olds varied from $84 \%$ to $86 \%$ in 1999-2000, while the comparable rates were $74 \%$ to $78 \%$ in 2011-12 [30].

During the NHANES physical examination, weight, height, and waist circumference were measured in a standardized fashion [31]. Body mass index (BMI) was calculated as weight (kg) divided by height $(\mathrm{m})^{2}$. BMI-for-age $\mathrm{z}$-scores and percentiles were calculated by expressing a child's BMI relative to children of the same sex and age who participated in national studies conducted from 1963-65 to 1988-94 [32]. Obesity is defined as a BMI $\geq 95$ th percentile (for children of the same sex and age) of the CDC Growth Charts [2,32] or a BMI $\geq 30 \mathrm{~kg} / \mathrm{m}^{2}$. Severe obesity is defined as a BMI $\geq 120 \%$ of the $95^{\text {th }}$ percentile in the CDC growth charts [33].

Waist circumference was measured to the nearest $1 \mathrm{~mm}$ just above the iliac crest using a steel measuring tape [31]. Although we primarily focus on waist circumference, some analyses examine secular trends in the waist to height ratio, a measure that has been proposed, in part, because levels of this ration remain fairly constant throughout childhood and adulthood [34].

\section{Statistical Methods}

All analyses used the examination sample weights and accounted for the sample design using the survey package in R [35,36]. Mean levels of BMI, waist circumference, and other body size measures are shown by sex and survey cycle; confidence intervals for the estimated prevalences of obesity were calculated as suggested by Korn and Graubard [37]. To summarize the secular trends in waist circumference, we focused on an 8-level categorical variable for survey cycle, with 1988-1994 (NHANES III) serving as the reference category. Waist circumference was predicted by survey cycle, race-ethnicity and age in one regression model, and to examine whether differences across studies were independent of BMI, BMI was included as an additional predictor in a second model. All analyses controlled for race and age to exclude the possibility that changes in waist circumference over time were attributable to changes in these characteristics. Both BMI and age were modeled using natural splines [38] to account for possible non-linearity. We assessed the possibility that in the BMI-adjusted models, the independent secular increase in waist circumference varied by race-ethnicity or age by including various interaction terms in the regression models. Similar models, but with a linear term for survey year, were constructed to assess the trend in waist circumference from 1988-1994 or 1999-2000 through 2011-2012.

Of the 26,981 6- to 19-year-olds who had a weight and height measurements, 548 (2\%) were missing information on waist circumference. The distributions of sex, race-ethnicity and BMI levels among these 548 children, however, did not differ from those of the other 26,433 children who had a measured waist circumference.

\section{Ethics Statement}

The NHANES protocol, including the consent procedure for minors, was approved by the Research Ethics Review Board of the National Center for Health Statistics. Written consent was obtained for all adults ( $\geq 18$ years of age) and written, parental permission was obtained for minors under the age of 18 years. Children aged 7 to 17 years were also asked to provide documented assent. 


\section{Results}

Table 1 and Fig 1 show mean levels of the body size measures and the prevalence of obesity in each survey from 1988-1994 through 2011-12 among 6- to 19-year-olds. Over this approximately 20 -year period, the mean waist circumference increased by $3.7 \mathrm{~cm}$ among boys and by $6.0 \mathrm{~cm}$ among girls. In addition, the mean BMI-for-age z-score increased by 0.25 to $0.30 \mathrm{SDs}$, and the prevalence of obesity increased by about 7 (boys) and 10 (girls) percentage points. As shown in Fig 1, most of the BMI and waist circumference increases occurred between 1988-94 and 2003-04. Over the approximately 20 -year period, the mean BMI of boys increased by $5.7 \%$ (from 20.1 to $21.2 \mathrm{~kg} / \mathrm{m}^{2}$ ) and the mean waist circumference increased by $5.3 \%$ (from 70.6 to $74.3 \mathrm{~cm}$ ), while among girls, the percentage changes were $7.7 \%$ (BMI) and $8.7 \%$ (waist circumference). These similarities reflect the very strong cross-sectional correlation $(\mathrm{r}=0.95)$ between BMI and waist circumference.

Fig 2 shows the mean and 95\% CI for the race- and age-adjusted differences in waist circumference (triangles and dotted CIs), between children in 1988-1994 (referent category in the regression models) and those in each subsequent survey. The mean waist circumference was substantially higher in 2003-04 than in 1988-94 (mean differences: $+4 \mathrm{~cm}$, boys; $+5 \mathrm{~cm}$, girls), but remained fairly stable subsequently. Including BMI as an additional covariate in these regression models (solid circles and lines) greatly reduced the differences among both boys and girls. Based on these BMI-adjusted regression models, the estimated difference in waist circumference between levels in 1988-94 and those in each subsequent survey ranged from $0.2 \mathrm{~cm}$ (2009-10) to $1.1 \mathrm{~cm}$ (2003-04) among boys and from $1.5 \mathrm{~cm}$ (1999-2000) to $2.5 \mathrm{~cm}(2005-06)$

Table 1. Mean levels (or prevalence) of various measures of body size among 6- to 19-year-olds from 1988-94 through 2011-12.

\begin{tabular}{|c|c|c|c|c|c|c|c|c|}
\hline Sex & Year & $\begin{array}{l}\text { Sample } \\
\text { Size }\end{array}$ & $\begin{array}{l}\text { Waist } \\
\text { (cm) }\end{array}$ & Waist/Height & $\begin{array}{c}\text { BMI } \\
\left(\mathrm{kg} / \mathrm{m}^{2}\right)\end{array}$ & $\begin{array}{l}\text { BMI-for-age } \\
\text { Z-Score }\end{array}$ & $\begin{array}{l}\text { Prevalence of Obesity } \\
\qquad(95 \% \mathrm{Cl})\end{array}$ & $\begin{array}{c}\text { Prevalence of Severe } \\
\text { Obesity }(95 \% \mathrm{Cl})\end{array}$ \\
\hline \multirow[t]{8}{*}{ Boys } & $\begin{array}{c}1988- \\
1994\end{array}$ & 3106 & $70.6 \pm 0.4^{a}$ & $0.459 \pm 0.002$ & $20.1 \pm 0.1$ & $0.25 \pm 0.03$ & $11.7(9.8,13.7)^{b}$ & $3.2(2.1,4.7)$ \\
\hline & $\begin{array}{l}1999- \\
2000\end{array}$ & 1684 & $72.6 \pm 0.9$ & $0.472 \pm 0.004$ & $20.7 \pm 0.3$ & $0.39 \pm 0.07$ & $15.5(12.7,18.5)$ & $4.5(2.6,7.0)$ \\
\hline & 2001-02 & 1735 & $74.1 \pm 0.4$ & $0.477 \pm 0.002$ & $21.1 \pm 0.1$ & $0.43 \pm 0.04$ & $17.5(15.2,20.0)$ & $6.4(5.0,8.0)$ \\
\hline & 2003-04 & 1570 & $74.9 \pm 0.8$ & $0.482 \pm 0.004$ & $21.3 \pm 0.3$ & $0.52 \pm 0.05$ & $18.9(15.4,22.8)$ & $5.6(3.6,8.2)$ \\
\hline & 2005-06 & 1615 & $74.1 \pm 0.8$ & $0.477 \pm 0.003$ & $21.1 \pm 0.3$ & $0.44 \pm 0.06$ & $17.5(13.5,22.1)$ & $5.7(3.7,8.3)$ \\
\hline & 2007-08 & 1212 & $74.7 \pm 0.7$ & $0.479 \pm 0.004$ & $21.4 \pm 0.3$ & $0.49 \pm 0.06$ & $20.3(17.0,24.0)$ & $6.4(4.3,9.1)$ \\
\hline & $2009-10$ & 1264 & $74.5 \pm 0.7$ & $0.478 \pm 0.003$ & $21.5 \pm 0.3$ & $0.52 \pm 0.04$ & $20.2(17.0,23.8)$ & $7.4(5.0,10.6)$ \\
\hline & 2011-12 & 1235 & $74.3 \pm 0.6$ & $0.479 \pm 0.003$ & $21.2 \pm 0.2$ & $0.50 \pm 0.05$ & $18.3(14.9,22.2)$ & $6.6(4.1,9.8)$ \\
\hline \multirow[t]{8}{*}{ Girls } & $\begin{array}{c}1988- \\
1994\end{array}$ & 3165 & $69.3 \pm 0.5$ & $0.463 \pm 0.002$ & $20.3 \pm 0.2$ & $0.26 \pm 0.04$ & $10.5(8.9,12.4)$ & $2.9(1.9,4.3)$ \\
\hline & $\begin{array}{l}1999- \\
2000\end{array}$ & 1589 & $72.2 \pm 0.6$ & $0.484 \pm 0.003$ & $21.0 \pm 0.2$ & $0.43 \pm 0.04$ & $15.1(12.7,17.9)$ & $4.1(2.8,5.8)$ \\
\hline & 2001-02 & 1710 & $72.8 \pm 0.7$ & $0.486 \pm 0.004$ & $21.1 \pm 0.3$ & $0.45 \pm 0.05$ & $15.5(12.2,19.3)$ & $4.6(3.1,6.4)$ \\
\hline & 2003-04 & 1501 & $74.5 \pm 0.7$ & $0.494 \pm 0.004$ & $21.5 \pm 0.3$ & $0.53 \pm 0.05$ & $16.5(13.5,19.9)$ & $5.1(3.6,6.9)$ \\
\hline & 2005-06 & 1582 & $74.0 \pm 0.8$ & $0.493 \pm 0.004$ & $21.3 \pm 0.3$ & $0.45 \pm 0.04$ & $16.1(12.1,20.7)$ & $5.5(3.7,7.8)$ \\
\hline & 2007-08 & 1126 & $73.9 \pm 0.8$ & $0.492 \pm 0.004$ & $21.4 \pm 0.2$ & $0.45 \pm 0.05$ & $17.9(14.6,21.5)$ & $5.1(3.3,7.4)$ \\
\hline & 2009-10 & 1161 & $74.2 \pm 0.5$ & $0.491 \pm 0.002$ & $21.5 \pm 0.2$ & $0.49 \pm 0.04$ & $16.5(14.9,18.2)$ & $5.7(4.2,7.6)$ \\
\hline & 2011-12 & 1178 & $75.3 \pm 0.8$ & $0.500 \pm 0.005$ & $21.9 \pm 0.3$ & $0.57 \pm 0.06$ & $20.6(17.7,23.7)$ & $6.7(4.7,9.2)$ \\
\hline
\end{tabular}

a Values are mean \pm SE or prevalence $(95 \% \mathrm{Cl})$

${ }^{\text {b }}$ Based on a BMI-for-age $\geq 95$ th percentile of the $2000 \mathrm{CDC}$ Growth Charts (reference \#31) or a BMl $\geq 30 \mathrm{~kg} / \mathrm{m}^{2}$ 




Fig 1. Mean levels of waist circumference, WHtR, BMI-for-age z-score and obesity among 6- to 19-year-olds from 1988-94 through 2011-12. Boys are represented by the solid, grey line.

doi:10.1371/journal.pone.0141056.g001 


\section{Adjusted for BMI: · $\triangle \cdot$ No $\rightarrow$ Yes}

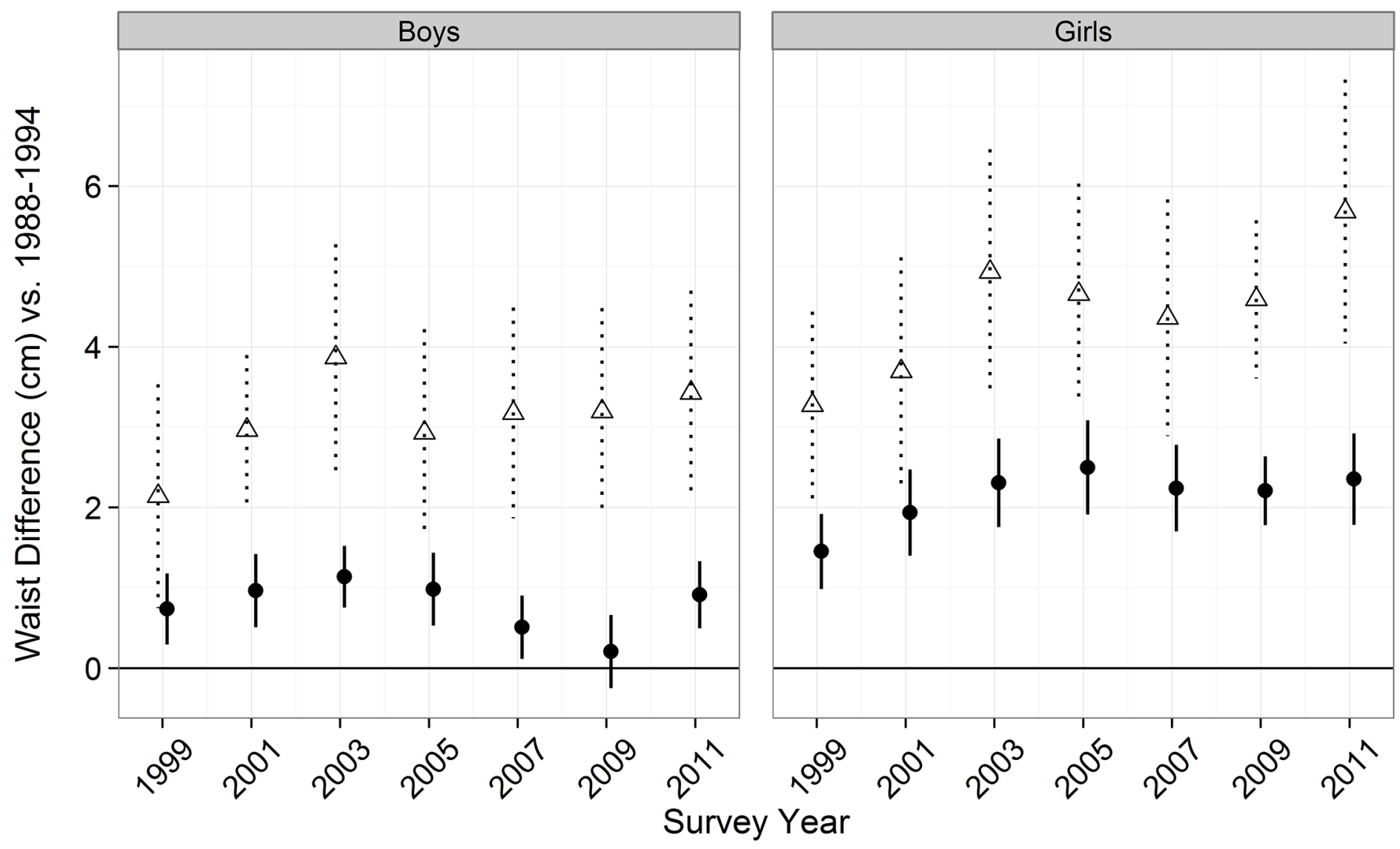

Fig 2. Regression coefficients and Cls for the difference in the mean waist circumference between 1988-94 and each subsequent survey cycle. Estimates were based on a regression model that included survey as a categorical level with 1988-94 as the reference category. The open triangles are estimates from models that included race and age, while the black circles are estimates from models that included BMI as an additional predictor. Age and BMI were modeled using natural splines with 3 knots. The $95 \%$ Cls for each estimate are also shown.

doi:10.1371/journal.pone.0141056.g002 
Table 2. Change in waist circumference $(\mathrm{cm})$ among 6- to 19-year-olds.

Secular Change Through 2011-12

\begin{tabular}{|c|c|c|c|c|}
\hline \multirow[b]{2}{*}{ Classification of Year } & \multirow[b]{2}{*}{ Sex } & \multirow[b]{2}{*}{ Adjustment for $B M I^{a}$} & \\
\hline & & & Starting in 1988-1994 & Starting in 1999-2000 \\
\hline \multirow[t]{4}{*}{ Linear Trend $^{\mathrm{b}}$} & Boys & No & $1.6(1.0,2.1)$ & $0.6(-0.4,1.7)$ \\
\hline & & Yes & $0.2(0.02,0.4)$ & $-0.3(-0.6,0.0)$ \\
\hline & Girls & No & $2.5(1.9,3.1)$ & $1.5(0.4,2.6)$ \\
\hline & & Yes & $1.1(0.9,1.3)$ & $0.6(0.2,0.9)$ \\
\hline \multirow[t]{4}{*}{ Categorical $^{\mathrm{C}}$} & Boys & No & $3.5(2.2,4.8)$ & $1.2(-0.5,2.9)$ \\
\hline & & Yes & $1.0(0.6,1.4)$ & $0.2(-0.3,0.6)$ \\
\hline & Girls & No & $5.8(4.1,7.5)$ & $2.4(0.7,4.1)$ \\
\hline & & Yes & $2.4(1.9,3.0)$ & $0.9(0.4,1.4)$ \\
\hline
\end{tabular}

a Both models (without and with BMl as a covariate) control for race and age

${ }^{b}$ Linear trends estimates are change in waist circumference per 10 years for the period starting in either 1988-94 or in 1999-2000 and ending in 201112. $95 \%$ Cls are shown in parentheses.

${ }^{c}$ Categorical estimates of waist circumference represent the difference in waist circumference between levels in 1988-94 or 1999-2000 and levels in 2011-12. 95\% Cls are shown in parentheses.

doi:10.1371/journal.pone.0141056.t002

Adjusted for BMI: $\cdots \Delta \cdots$ no $\rightarrow$ yes
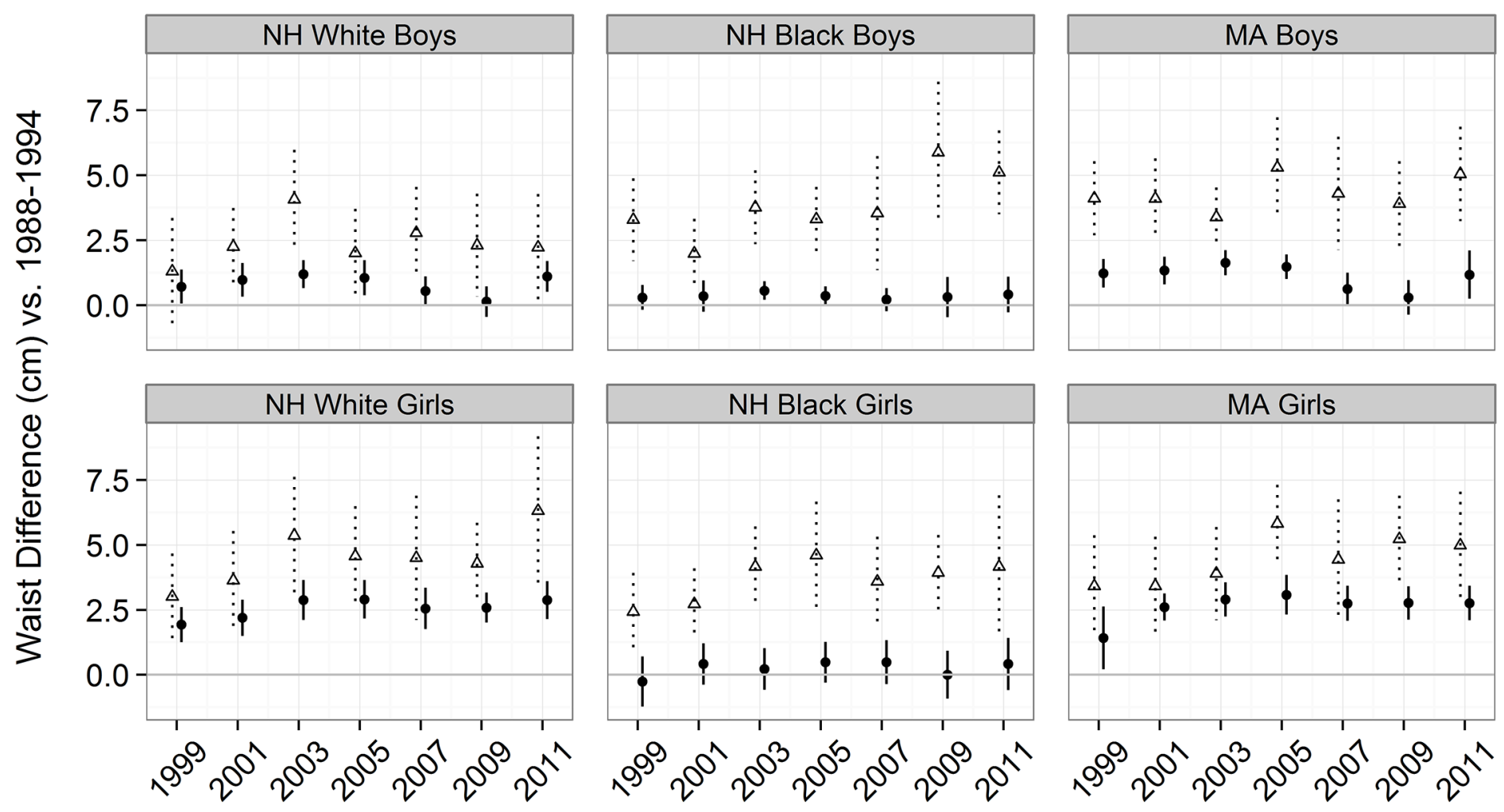

\section{Survey Year}

Fig 3. Regression coefficients showing the difference in mean waist circumference between 1988-94 and each subsequent survey by sex (boys, top row) and race-ethnicity (columns). The open triangles represent estimates that are adjusted only for age, and the black circles are estimates from models that adjust for both age and BMI.

doi:10.1371/journal.pone.0141056.g003 
$\mathrm{NH}$ black boys and $\mathrm{NH}$ black girls, but by only $70 \%$ (boys) and $40 \%$ (girls) among $\mathrm{NH}$ white and Mexican-American children.

\section{Discussion}

Our results indicate that although the mean waist circumference of 6- to 19-year-olds in the U. S. has increased by $4 \mathrm{~cm}$ (boys) to $6 \mathrm{~cm}$ (girls) since 1988-1994, much of this increase is due to factors that have led to increases in both BMI and waist circumference. In the current study, adjustment for BMI reduced the magnitude of the secular increase in waist circumference over the approximately 20 -year period by about $75 \%$ among boys and $50 \%$ among girls. Furthermore, there has not been a statistically significant increase in the mean waist circumference of boys since 1999-2000. Additional analyses in the current study indicated that adjustment for weight, rather than BMI, resulted in very similar results concerning the independent increase in waist circumference.

In parallel with the secular increases in waist circumference that have been reported among adults [27,39], the waist circumference of children in various countries has increased over the last 20 years $[19,20,23-25,40,41]$. Although few of these studies attempted to determine if the change in waist circumference was independent of BMI, a recent review concluded that to some extent, there have been independent increases in waist circumference [20]. For example, some investigators have found increases in waist circumference but not in BMI [24] or that the proportional increases in waist circumference have been larger than those for BMI [25,42]. Furthermore, as assessed by skinfold thicknesses, it appears that the distribution of body fatness has become more centralized [43]. Several studies among adults have also concluded that the secular trends in waist circumference in the U.S. have been independent of BMI [27,44,22]. Few of these studies, however, have attempted to quantify how much of the secular increase in waist circumference was independent of the increase in BMI.

In contrast to these results, we found that the proportional changes in waist circumference were similar to those in BMI from 1988-94 through 2011-12, and that only $1 / 4$ (boys) and $1 / 2$ (girls) of the secular increase in waist circumference was independent of BMI. The differences between our results and those of previous studies concerning the BMI-independent increases in waist circumference may be due to differences in time periods, statistical methods, and measurement techniques. For example, some studies [26,22] included data from the first National Health and Examination Survey (1959-1962), even though waist circumference was measured at a different location than in more recent NHANES studies [21,31] (http://www.cdc.gov/nchs/ data/nhanes/nhes123/1003). Furthermore, although Walls et al. [27] emphasized the approximately $0.75 \mathrm{~cm}$ independent increase in waist circumference from 1988-94 through 20052006, there was no mention that BMI adjustment reduced this estimate by about $80 \%$.

The race-ethnicity difference that we observed, with BMI accounting for about $90 \%$ of the secularly increase in the waist circumference of both $\mathrm{NH}$ black boys and $\mathrm{NH}$ black girls, was unexpected and the reasons for this interaction are uncertain. Over the 20-year period, $\mathrm{NH}$ black children showed a larger secular increase in BMI $\left(\sim 2 \mathrm{~kg} / \mathrm{m}^{2}\right)$ than did $\mathrm{NH}$ white and Mexican-American children $\left(\sim 1.0\right.$ to $\left.1.3 \mathrm{~kg} / \mathrm{m}^{2}\right)$. Differences in the waist circumference trends across race-ethnicity groups were smaller, ranging from $+4.6 \mathrm{~cm}$ (whites) to $+5.4 \mathrm{~cm}$ (blacks and Mexican-Americans). As compared to white adults, blacks have less intra-abdominal fat than do whites [45] and we found that the mean, BMI-adjusted waist circumference was $3 \mathrm{~cm}$ lower among NH black children than among other children (data not shown). However, the proportion of abdominal fat that is in the subcutaneous region is higher among black adults than among whites and Hispanics [46], and this fat depot appears to be the most strongly 
associated with BMI [47]. If similar differences exist among children, this may explain why BMI adjustment had the largest effect on the waist circumference trends among NH black children.

Several of the results of the current study are similar to our recent findings among adults [21]. Although there were large secular increases in waist circumference since 1999-2000, with mean increases of $2 \mathrm{~cm}$ among men and $4 \mathrm{~cm}$ among women, controlling for BMI reduced this increase by approximately $90 \%$ among men and $20 \%$ among women. A recent analyses of secular trends in abdominal obesity from 2003-04 through 2011-12 among children and adolescents in NHANES [41] reported that there was no change in waist circumference since 2003 04, but this may not be the optimal starting point for an analysis of secular trends. As seen in Table 1 and Fig 1, levels of waist circumference and BMI-for-age appear to have been slightly higher in 2003-04 than in adjacent cycles.

Several possible reasons explanations have been proposed for the observed secular increases in the waist circumference of adults [27,22], including changes in energy intake and physical activity, the prevalence of endocrine disruptors, and treatments for depression [48] and obesity [49]. It is also possible that changes in drug treatment for attention-deficit/hyperactivity disorder (ADHD) [50] may play a role in these secular trends, but it is likely that this would influence trends in adult obesity more than child obesity [51,52]. A difficulty in assessing possible mechanisms is that the relation of these characteristics to obesity is likely to be much weaker than is the cross-sectional correlation $(r>0.90)$ between BMI and waist circumference.

It is, however, possible that BMI-independent increases in waist circumference may simply reflect that fat mass is more strongly associated with waist circumference than with BMI. Although BMI and waist circumference are strongly correlated, there is some evidence [53] among adults that the correlation between longitudinal changes in these 2 measure of body size are weaker than are the cross-sectional correlations. For example, over a 5-year period, the correlation between weight change and waist circumference change was $\mathrm{r} \sim 0.70$.

There are several limitations of the current study that should be considered in the interpretation of our results. Although about $2 \%$ of the children who had a measured BMI were missing data for waist circumference, the probability of missingness was not related to BMI and the exclusion of these children is unlikely to have biased our findings. It should be realized, however, that the measurement of waist circumference in NHANES is just above the iliac [31], a location that has been characterized as being difficult to accurately measure [54]. In contrast, other studies of children and adolescents have measured waist circumference midway between the lower rib and the top of the iliac crest $[24,25,40,42]$. The relatively small $(\mathrm{N} \leq 1700)$ sexspecific sample sizes, combined with the multi-stage cluster design of NHANES, also resulted in the 2-year estimates being relatively imprecise. It should also be noted that the magnitudes of the secular increases in waist circumference among girls were increased with age $(\mathrm{p}<0.01$ for interaction) with 16- to 19-year-old girls, for example, showing more than a $3.0 \mathrm{~cm}$ (BMIindependent) increase over the approximately 20 -year period.

Our results indicate that among children, levels of BMI and waist circumference are, to some extent, particularly among boys, responding similarly to various environmental and lifestyle characteristics that are causing levels of both measures to have increased since 1988-1994. These increases, however, appear to have plateaued or slowed in recent years. The very strong correlation between waist circumference and BMI makes it important to consider BMIadjusted, rather than simply crude, change in levels of waist circumference over time. Possible reasons for the very large effects of BMI adjustment on the secular increase in waist circumference among NH black children should be further explored. 


\section{Acknowledgments}

The findings and conclusions in this report are those of the authors and do not necessarily represent the position of the Centers for Disease Control and Prevention.

\section{Author Contributions}

Conceived and designed the experiments: DF. Analyzed the data: DF EF BK. Wrote the paper: DF. Editing and revisions: EF BK.

\section{References}

1. Kuczmarski RJ, Ogden CL, Grummer-Strawn LM, Flegal KM, Guo SS, Wei R, et al. CDC growth charts: United States. Adv Data. 2001/02/24 ed. 2000; 2000: 1-27.

2. Ogden CL, Flegal KM. Changes in terminology for childhood overweight and obesity. Natl Health Stat Report. 2010; 1-5.

3. Ogden CL, Flegal K, Carroll MD, Johnson CL. Prevalence and trends in overweight among US children and adolescents, 1999-2000. JAMA. 2002; 288: 1728-1732. joc21462 [pii] PMID: 12365956

4. Ogden CL, Carroll MD, Kit BK, Flegal KM. Prevalence of childhood and adult obesity in the United States, 2011-2012. JAMA. 2014; 311: 806-14. doi: 10.1001/jama.2014.732 PMID: 24570244

5. Fryar C, Carroll MD, Ogden CL. Prevalence of overweight, obesity, and extreme obesity among adults: United States, 1960-1962 through 2011-2012 [Internet]. 2014. Available: http://www.cdc.gov/nchs/ data/hestat/obesity_adult_11_12/obesity_adult_11_12.pdf

6. Sun Q, Dam RM Van, Spiegelman D, Heymsfield SB, Willett WC, Hu FB, et al. Comparison of dualenergy $\mathrm{x}$-ray absorptiometric and anthropometric measures of adiposity in relation to adiposity-related biologic factors. Am J Epidemiol. 2010; 172: 1442-1454. doi: 10.1093/aje/kwq306 PMID: 20952596

7. Hariri AA, Oliver NS, Johnston DG, Stevenson JC, Godsland IF. Adiposity measurements by BMI, skinfolds and dual energy $X$-ray absorptiometry in relation to risk markers for cardiovascular disease and diabetes in adult males. Dis Markers. 2013; 35: 753-64. doi: 10.1155/2013/763907 PMID: 24347796

8. Steinberger J, Jacobs DR, Raatz S, Moran A, Hong CP, Sinaiko AR. Comparison of body fatness measurements by $\mathrm{BMI}$ and skinfolds vs dual energy $\mathrm{X}$-ray absorptiometry and their relation to cardiovascular risk factors in adolescents. Int J Obes. 2005/07/27 ed. 2005; 29: 1346-1352.

9. Wormser D, Kaptoge S, Di Angelantonio E, Wood AM, Pennells L, Thompson A, et al. Separate and combined associations of body-mass index and abdominal adiposity with cardiovascular disease: collaborative analysis of 58 prospective studies. Lancet. 2011; 377: 1085-95. doi: 10.1016/S0140-6736 (11)60105-0 PMID: 21397319

10. Despres JP, Lemieux I, Bergeron J, Pibarot P, Mathieu P, Larose E, et al. Abdominal obesity and the metabolic syndrome: contribution to global cardiometabolic risk. Arterioscler Thromb Vasc Biol. 2008/ 03/22 ed. 2008; 28: 1039-1049. ATVBAHA.107.159228 [pii] doi: 10.1161/ATVBAHA.107.159228 PMID: 18356555

11. Nyamdorj R, Qiao Q, Lam TH, Tuomilehto J, Ho SY, Pitkäniemi J, et al. BMI compared with central obesity indicators in relation to diabetes and hypertension in Asians. Obesity (Silver Spring). 2008; 16: 1622-35. doi: 10.1038/oby.2008.73

12. de Hollander EL, Bemelmans WJ, Boshuizen HC, Friedrich N, Wallaschofski H, Guallar-Castillón $P$, et al. The association between waist circumference and risk of mortality considering body mass index in 65- to 74-year-olds: a meta-analysis of 29 cohorts involving more than 58000 elderly persons. Int $\mathrm{J}$ Epidemiol. 2012; 41: 805-17. doi: 10.1093/ije/dys008 PMID: 22467292

13. Kodama S, Horikawa C, Fujihara K, Heianza Y, Hirasawa R, Yachi Y, et al. Comparisons of the strength of associations with future type 2 diabetes risk among anthropometric obesity indicators, including waist-to-height ratio: a meta-analysis. Am J Epidemiol. 2012; 176: 959-69. doi: 10.1093/aje/kws172 PMID: 23144362

14. Carmienke S, Freitag MH, Pischon $\mathrm{T}$, Schlattmann $\mathrm{P}$, Fankhaenel $\mathrm{T}$, Goebel $\mathrm{H}$, et al. General and abdominal obesity parameters and their combination in relation to mortality: a systematic review and meta-regression analysis. Eur J Clin Nutr. Nature Publishing Group; 2013; 67: 573-85. doi: 10.1038/ ejcn.2013.61 PMID: 23511854

15. Savva SC, Lamnisos D, Kafatos AG. Predicting cardiometabolic risk: waist-to-height ratio or BMI. A meta-analysis. Diabetes Metab Syndr Obes. 2013; 6: 403-19. doi: 10.2147/DMSO.S34220 PMID: 24179379 
16. Reilly JJ, Kelly J, Wilson DC. Accuracy of simple clinical and epidemiological definitions of childhood obesity: systematic review and evidence appraisal. Obes Rev. 2010; 11:645-55. doi: 10.1111/j.1467789X.2009.00709.x PMID: 20059704

17. Freedman DS, Kahn HS, Mei Z, Grummer-Strawn LM, Dietz WH, Srinivasan SR, et al. Relation of body mass index and waist-to-height ratio to cardiovascular disease risk factors in children and adolescents: the Bogalusa Heart Study. Am J Clin Nutr. 2007/07/10 ed. 2007; 86: 33-40. 86/1/33 [pii] PMID: 17616760

18. Katzmarzyk PT, Bouchard C. Where is the beef? Waist circumference is more highly correlated with $\mathrm{BMI}$ and total body fat than with abdominal visceral fat in children. Int J Obes (Lond). 2014; 38: 753-4. doi: 10.1038/ijo.2013.170

19. Janssen I, Shields M, Craig CL, Tremblay MS. Prevalence and secular changes in abdominal obesity in Canadian adolescents and adults, 1981 to 2007-2009. Obes Rev. 2011; 12: 397-405. doi: 10.1111/ j.1467-789X.2010.00815.x PMID: 20977603

20. Visscher TLS, Heitmann BL, Rissanen A, Lahti-Koski M, Lissner L. A break in the obesity epidemic? Explained by biases or misinterpretation of the data? Int J Obes (Lond). 2014; doi: 10.1038/ijo.2014.98

21. Freedman DS, Ford ES. Are the recent secular increases in the waist circumference of adults independent of changes in BMI? Am J Clin Nutr. 2015; 101: 425-31. doi: 10.3945/ajcn.114.094672 PMID: 25733625

22. Elobeid MA, Desmond RA, Thomas O, Keith SW, Allison DB. Waist circumference values are increasing beyond those expected from BMI increases. Obesity (Silver Spring). 2007; 15: 2380-3. doi: 10. 1038/oby.2007.282

23. Li C, Ford ES, Mokdad AH, Cook S. Recent trends in waist circumference and waist-height ratio among US children and adolescents. Pediatrics. 2006; 118: e1390-8. doi: 10.1542/peds.2006-1062 PMID: 17079540

24. Kolle E, Steene-Johannessen J, Holme I, Andersen LB, Anderssen SA. Secular trends in adiposity in Norwegian 9-year-olds from 1999-2000 to 2005. BMC Public Health. 2009; 9: 389. doi: 10.1186/14712458-9-389 PMID: 19828037

25. McCarthy HD, Ellis SM, Cole TJ. Central overweight and obesity in British youth aged 11-16 years: cross sectional surveys of waist circumference. BMJ. 2003; 326: 624. doi: 10.1136/bmj.326.7390.624 PMID: 12649234

26. Okosun IS, Chandra KMD, Boev A, Boltri JM, Choi ST, Parish DC, et al. Abdominal adiposity in U.S. adults: prevalence and trends, 1960-2000. Prev Med (Baltim). 2004; 39: 197-206. doi: 10.1016/j. ypmed.2004.01.023

27. Walls HL, Stevenson CE, Mannan HR, Abdullah A, Reid CM, McNeil JJ, et al. Comparing trends in BMI and waist circumference. Obesity (Silver Spring). 2011; 19: 216-9. doi: 10.1038/oby.2010.149

28. Björntorp P. Do stress reactions cause abdominal obesity and comorbidities? Obes Rev. 2001; 2: 7386. PMID: 12119665

29. Centers for Disease Control and Prevention. National Center for Health Statistics: National Health and Nutrition Examination Survey Data [Internet]. 2012. Available: http://www.cdc.gov/nchs/nhanes/ nhanes_questionnaires.htm

30. NHANES—Response Rates and Population Totals [Internet]. [cited 21 Jan 2015]. Available: http:// www.cdc.gov/nchs/nhanes/response_rates_cps.htm

31. National Center for Health Statistics (NCHS). Anthropometry Procedures Manual. National Health and Nutrition Examination Survy (NHANES) [Internet]. 2011 [cited 22 May 2014]. Available: http://www.cdc. gov/nchs/data/nhanes/nhanes_11_12/Anthropometry_Procedures_Manual.pdf

32. Kuczmarski RJ, Ogden CL, Guo SS, Grummer-Strawn LM, Flegal KM, Mei Z, et al. 2000 CDC Growth Charts for the United States: methods and development. Vital Health Stat 11. 2002/06/05 ed. 2002; 11: 1-190.

33. Flegal KM, Wei R, Ogden CL, Freedman DS, Johnson CL, Curtin LR. Characterizing extreme values of body mass index-for-age by using the 2000 Centers for Disease Control and Prevention growth charts. Am J Clin Nutr. 2009; 90: 1314-1320. doi: 10.3945/ajcn.2009.28335 PMID: 19776142

34. Ashwell M, Gunn P, Gibson S. Waist-to-height ratio is a better screening tool than waist circumference and BMI for adult cardiometabolic risk factors: systematic review and meta-analysis. Obes Rev. 2012; 13: 275-86. doi: 10.1111/j.1467-789X.2011.00952.x PMID: 22106927

35. R Core Team. R: A language and environment for statistical computing. R Foundation for Statistical Computing: Vienna, Austria. [Internet]. 2015. Available: http://www.r-project.org/

36. Lumley T. Analysis of complex survey samples. Hoboken, N.J.: John Wiley \& Sons; 2010.

37. Korn EL, Graubard B. Confidence intervals for proportions with small expected number of positive counts estimated from survey data. Surv Methodol. 1998; 24: 193-201. 
38. Harrell FE. Regression Modeling Strategies: With Applications to Linear Models, Logistic Regression, and Survival Analysis. Springer series in statistics. New York: Springer; 2001.

39. Ford ES, Maynard LM, Li C. Trends in mean waist circumference and abdominal obesity among US adults, 1999-2012. JAMA. 2014; 312: 1151-1153. doi: 10.1001/jama.2014.8362 PMID: 25226482

40. Moreno LA, Sarría A, Fleta J, Marcos A, Bueno M. Secular trends in waist circumference in Spanish adolescents, 1995 to 2000-02. Arch Dis Child. 2005; 90: 818-9. doi: 10.1136/adc.2004.067066 PMID: 16040878

41. Xi B, Mi J, Zhao M, Zhang T, Jia C, Li J, et al. Trends in abdominal obesity among U.S. children and adolescents. Pediatrics. 2014; 134: e334-9. doi: 10.1542/peds.2014-0970 PMID: 25049347

42. McCarthy HD, Jarrett K V, Emmett PM, Rogers I. Trends in waist circumferences in young British children: a comparative study. Int J Obes (Lond). 2004/12/01 ed. 2005; 29: 157-62. doi: 10.1038/sj.ijo. 0802849

43. Moreno LA, Fleta J, Sarria A, Rodriguez G, Gil C, Bueno M. Secular changes in body fat patterning in children and adolescents of Zaragoza (Spain), 1980-1995. Int J Obes Relat Metab Disord. 2001/12/26 ed. 2001; 25: 1656-1660. doi: 10.1038/sj.ijo.0801803 PMID: 11753587

44. Ford ES, Mokdad AH, Giles WH. Trends in waist circumference among U.S. adults. Obes Res. 2003; 11: 1223-31. doi: 10.1038/oby.2003.168 PMID: 14569048

45. Carroll JF, Chiapa AL, Rodriquez M, Phelps DR, Cardarelli KM, Vishwanatha JK, et al. Visceral fat, waist circumference, and BMl: impact of race/ethnicity. Obesity (Silver Spring). 2008; 16: 600-7. doi: 10.1038/oby.2007.92

46. Grundy SM, Neeland IJ, Turer AT, Vega GL. Waist circumference as measure of abdominal fat compartments. J Obes. 2013; 2013: 454285. doi: 10.1155/2013/454285 PMID: 23762536

47. Klein S, Allison DB, Heymsfield SB, Kelley DE, Leibel RL, Nonas C, et al. Waist Circumference and Cardiometabolic Risk: a Consensus Statement from Shaping America's Health: Association for Weight Management and Obesity Prevention; NAASO, the Obesity Society; the American Society for Nutrition; and the American Diabetes Associat. Obesity (Silver Spring). 2007; 15: 1061-7. doi: 10.1038/oby. 2007.632

48. Ma Y, Balasubramanian R, Pagoto SL, Schneider KL, Hébert JR, Phillips LS, et al. Relations of depressive symptoms and antidepressant use to body mass index and selected biomarkers for diabetes and cardiovascular disease. Am J Public Health. 2013; 103: e34-43. doi: 10.2105/AJPH.2013.301394 PMID: 23763394

49. Aydin N, Topsever P, Kaya A, Karasakal M, Duman C, Dağar A. Orlistat, sibutramine, or combination therapy: which performs better on waist circumference in relation with body mass index in obese patients? Tohoku J Exp Med. 2004; 202: 173-80. PMID: 15065643

50. Visser SN, Danielson ML, Bitsko RH, Holbrook JR, Kogan MD, Ghandour RM, et al. Trends in the parent-report of health care provider-diagnosed and medicated attention-deficit/hyperactivity disorder: United States, 2003-2011. J Am Acad Child Adolesc Psychiatry. 2014; 53: 34-46.e2. doi: 10.1016/j. jaac.2013.09.001 PMID: 24342384

51. Schwartz BS, Bailey-Davis L, Bandeen-Roche K, Pollak J, Hirsch AG, Nau C, et al. Attention deficit disorder, stimulant use, and childhood body mass index trajectory. Pediatrics. 2014; 133: 668-76. doi: 10. 1542/peds.2013-3427 PMID: 24639278

52. Cortese S, Ramos Olazagasti MA, Klein RG, Castellanos FX, Proal E, Mannuzza S. Obesity in men with childhood ADHD: a 33-year controlled, prospective, follow-up study. Pediatrics. 2013; 131: e17318. doi: 10.1542/peds.2012-0540 PMID: 23690516

53. Peeters A, Magliano DJ, Backholer K, Zimmet $P$, Shaw JE. Changes in the rates of weight and waist circumference gain in Australian adults over time: a longitudinal cohort study. BMJ Open. 2014; 4: e003667. doi: 10.1136/bmjopen-2013-003667 PMID: 24440794

54. Wang J, Thornton JC, Bari S, Williamson B, Gallagher D, Heymsfield SB, et al. Comparisons of waist circumferences measured at 4 sites. Am J Clin Nutr. 2003/01/24 ed. 2003; 77: 379-84. PMID: 12540397 